\title{
AN ACQUIRED COAGULATION DEFECT IN A WOMAN
}

\author{
BY \\ J. R. O'BRIEN \\ From the Pathological Department, South Devon and East Cornwall Hospital, Plymouth
}

(RECEIVED FOR PUBLICATION JANUARY 9, 1953)

A prolonged clotting time is rare in women. Nine cases have been reported, and from Table I, which summarizes these and the present case, it will be seen that all except one occurred within a few months of childbirth. In all, the clinical story was surprisingly similar: all had deep ecchymoses, and most had epistaxis, haematuria, and often effusions into joints and melaena. One patient died of suffocation from haemorrhage into the tongue; some have continued unchanged for a number of years; some have slowly recovered, while the present patient recovered in a few months.

Laboratory investigation showed in all a normal bleeding time (except possibly in the present case), a normal platelet count, and a normal tourniquet test except in Madison and Quick's case (1945). The prothrombin time was normal in all cases in which it was performed. The Lee and White coagulation time was long in every case, and varied from half to two hours. In five there was evidence that an inhibitor was present which seemed to act either on the formation of thromboplastin or specifically against the antihaemophilic globulin. In two others there was fragmentary evidence to suggest that the patient's plasma and that from a haemophiliac were not mutually correcting. The present case falls into this group also.

The rarity of these cases, and the interest of the investigation of each case in relation to the then accepted theory of blood coagulation, seem to justify reporting the investigation of a further example of this mixed group, even though the patient's recovery prevented the fullest investigation.

\section{Case History}

A married woman, aged 35 , had had no relevant illness and gave a history with no haemorrhagic incidents until three months after the birth of her first baby. For the next three months she had a series of large, subcutaneous, spontaneous bruises and an attack of heavy, painless haematuria. These symptoms slowly cleared up and she has remained well for one year up to the present.

The routine investigations are presented in Table II. The bleeding time was considerably longer than the average normal figure in women, but occasionally

TABLE I

SUMMARY OF REPORTED CASES

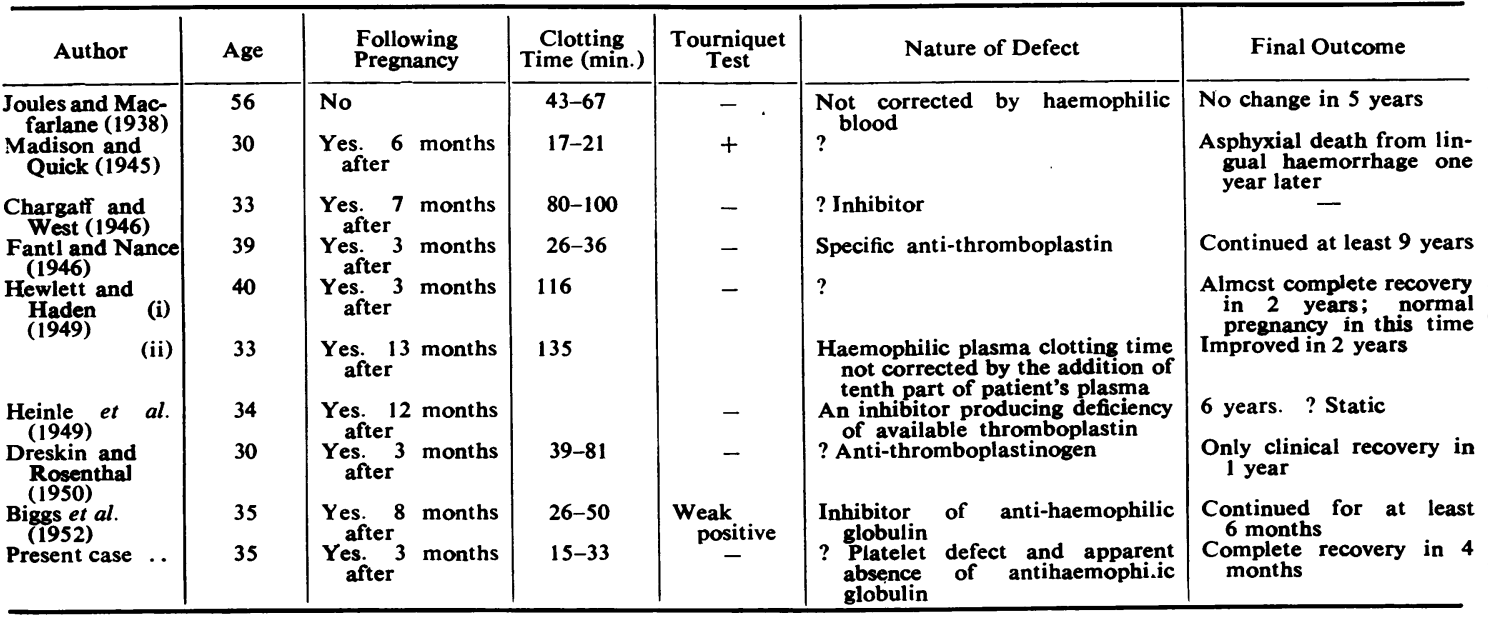


TABLE II ROU IINE INVESTIGATIONS

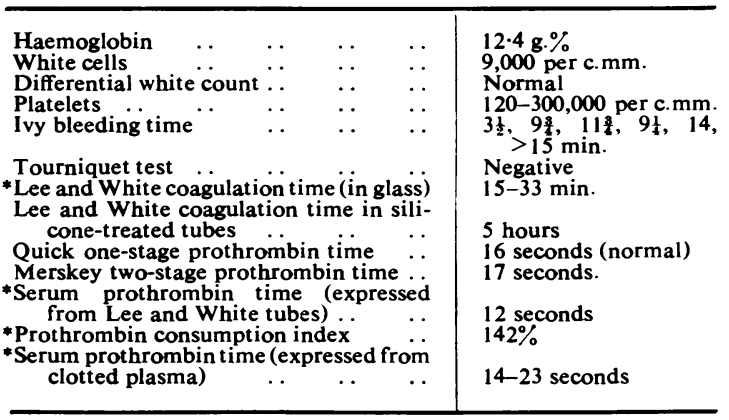

* These figures were obtained at the beginning of the illness.

such long figures are observed in otherwise normal people (O'Brien, 1950).

The evidence in Table II indicates that the defect is due to the inadequate conversion of prothrombin to thrombin. A normal amount of prothrombin seems to be present and it is able to function normally as indicated by the normal one-stage prothrombin time, but the intrinsic thromboplastin is inefficient. The factors thought to be necessary for the formation of thromboplastin are platelets, factor V, antihaemophilic globulin, factor VII (Koller, Loeliger, and Duckert, 1951), the Christmas factor (Biggs et al., 1952 ; Biggs, Douglas, and Macfarlane, 1953), and calcium. Any one or more of these factors may be deficient or prevented from working by a specific inhibitor.

\section{Technique}

Blood collected by a clean venepuncture was mixed with one tenth part of $3.8 \%$ sodium citrate and centrifuged at 1,500 r.p.m. for five minutes and the supernatant pipetted off.

When plasma relatively free of platelets and a platelet suspension was required, siliconed apparatus was used. Slow-spun plasma prepared as above was recentrifuged at 6,000 r.p.m. for 15 minutes and the supernatant called "high-spun plasma." The viscid mass at the bottom of the tube was drained dry by inversion, and emulsified into a volume of saline equal to one-third of the original plasma volume. A homogeneous suspension was not obtained. The brain thromboplastin used was made from acetonedried human brain and gave normal prothrombin times of 14 to 17 seconds. The calcium chloride solution was M-40. The fibrinogen was a $1 \%$ solution in saline of the human fibrinogen prepared by the Lister Institute. The prothrombin consumption index was estimated according to the technique of Mersky (Mersky, 1950). All experiments were carried out with the reacting tubes and solutions in a water-bath at $37^{\circ} \mathrm{C}$.

\section{Results}

The rate of formation of thrombin in recalcified plasma was watched by transferring sub-samples from the reacting tube into fibrinogen solution. The first appearance of thrombin was delayed until 11 minutes; it never reached normal concentration, and its disappearance was also delayed ; on occasion some was still present at the end of an hour. The range of sensitivity of the patient's plasma to variations in the calcium concentration was normal, as was its sensitivity to added thrombin.

The Absence of Inhibitors.-The addition of one volume of the patient's plasma to one volume of normal plasma caused no increase in the recalcification clotting time when compared with that of normal plasma diluted with one volume of saline. Tocantins, Carroll, and Holburn (1951) have shown that by diluting normal plasma with saline the recalcification time is first shortened, and in some patients the presence of an inhibitor may be exposed. The behaviour of this patient's plasma in such an experiment was comparable with that of normal plasma. The sensitivity of the patient's plasma to added thromboplastin, both brain and Russell viper venom, was compared with that of normal plasma. The plasma clotting time was shortened by high dilutions of thromboplastin, suggesting again that no inhibitor was present. The shortening was, however, not quite as great as that of normal plasma, but was of the same order as that found in haemophilic plasmas (Biggs and Macfarlane, 1951).

Activity of the Patient's Platelets.-Platelet suspensions from the patient were added, undiluted and in dilution, to high-spun plasma, and the accelerating effect on the coagulation time of these additions was compared with the coagulation time of the recalcified plasma alone. A normal platelet suspension prepared in parallel was used as a control. The acceleration effect on high-spun plasma from both the patient and a normal person was investigated at the same time.

From the results reported in Table III it will be seen that the suspensions of the patient's platelets are nearly, but not quite, as efficient as the normal control in accelerating the clotting of normal plasma, even when the suspension is considerably diluted. In contrast, the patient's platelets are considerably less efficient than the normal platelets in accelerating the clotting of her own high-spun plasma. It will have been observed that the platelet suspensions were not washed. Contamination with plasma might have explained this dis- 
TABLE III

COMPARISON OF PATIENT'S PLATELET ACTIVITY

\begin{tabular}{|c|c|c|c|c|c|c|c|c|}
\hline $\begin{array}{l}\text { Dilution of } \\
\text { Platelet } \\
\text { Suspension }\end{array}$ & & $\frac{1}{1}$ & $\frac{1}{5}$ & $\frac{1}{25}$ & $\frac{1}{125}$ & $\frac{1}{625}$ & $\frac{1}{3,225}$ & $\begin{array}{l}\text { Sal- } \\
\text { ine }\end{array}$ \\
\hline $\begin{array}{l}\text { Normal } \\
\text { high-spun } \\
\text { plasma }\end{array}$ & $\left.\begin{array}{c}\text { Patient's } \\
\text { platelets } \\
\text { Normal } \\
\text { platelets }\end{array}\right\}$ & $\begin{array}{l}1 \cdot 50 \\
1 \cdot 30\end{array}$ & $\begin{array}{l}1 \cdot 55 \\
1 \cdot 10\end{array}$ & $\begin{array}{l}2 \cdot 55 \\
1 \cdot 30\end{array}$ & $\begin{array}{l}2 \cdot 35 \\
2 \cdot 05\end{array}$ & $\begin{array}{l}2 \cdot 32 \\
3 \cdot 0\end{array}$ & $\begin{array}{l}3 \cdot 0 \\
2 \cdot 45\end{array}$ & $\begin{array}{l}3.45 \\
3.45\end{array}$ \\
\hline $\begin{array}{l}\text { Patient's } \\
\text { high-spun } \\
\text { plasma }\end{array}$ & 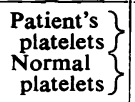 & $\begin{array}{l}6 \cdot 0 \\
1.45\end{array}$ & $\begin{array}{l}7 \cdot 0 \\
4 \cdot 0\end{array}$ & $\left|\begin{array}{r}10 \cdot 15 \\
7 \cdot 10\end{array}\right|$ & $\begin{array}{r}11 \cdot 30 \\
5 \cdot 30\end{array}$ & \begin{tabular}{|c|}
$12 \cdot 5$ \\
8.40
\end{tabular} & $\begin{array}{l}17 \cdot 0 \\
12 \cdot 15\end{array}$ & $\begin{array}{l}18 \cdot 0 \\
18 \cdot 0\end{array}$ \\
\hline
\end{tabular}

Time in minutes and seconds. To $0 \cdot 2 \mathrm{ml}$. of the plasma, $0.2 \mathrm{ml}$. of the platelet dilution was added, and finally $0.2 \mathrm{ml}$. of $\mathrm{M}-40 \mathrm{CaCl}_{2}$; $0 \cdot 2 \mathrm{ml}$. of normal saline was added in place of the platelet suspension in the control tubes.

crepancy, but dilutions of normal high-spun plasma greater than could have occurred in the preparation of the platelets had a minimal accelerating effect. These results suggest that the patient's platelets were at fault and that the plasma might lack a substance which normally reacts with platelets to produce thromboplastin.

Antihaemophilic Globulin.-The presence of antihaemophilic globulin in a patient's plasma can be demonstrated if haemophilic plasma corrects the patient's clotting defect as efficiently as does normal plasma, or if conversely a patient's plasma corrects the clotting defect of haemophilic plasma.

Four haemophiliacs were available. They all had typical clinical histories, long clotting times, an impaired prothrombin consumption, and were corrected by the addition of small quantities of normal plasma and were not significantly mutually correcting. (Later it was shown that none was a case of Christmas disease.)

TABLE IV

CLOTTING TIME OF MIXTURES OF PATIENT'S PLASMA AND HAEMOPHILIC PLASMAS AND DILU IIONS OF BOTH

\begin{tabular}{|c|c|c|c|c|c|c|}
\hline Mixture & $\begin{array}{l}\mathbf{P} \\
+ \\
\mathbf{S}\end{array}$ & $\begin{array}{l}\mathbf{P} \\
\stackrel{+}{\mathbf{H}}\end{array}$ & $\begin{array}{c}\mathbf{P} / 10 \\
\stackrel{+}{\mathbf{H}}\end{array}$ & $\begin{array}{c}\mathbf{P} / 100 \\
+ \\
\mathbf{H}\end{array}$ & $\begin{array}{l}\mathbf{S} \\
+ \\
\mathbf{H}\end{array}$ & $\begin{array}{c}\mathbf{P} \\
\stackrel{+}{+} \\
\mathbf{N} / 10\end{array}$ \\
\hline $\begin{array}{l}\text { Nov. } 9,1951 \\
\begin{array}{l}\not 1 \\
\text { Dec. } 5,1951\end{array} \text {.. } \\
\end{array}$ & $\begin{array}{l}8 \cdot 20 \\
7 \cdot 25 \\
4 \cdot 40\end{array}$ & $\begin{array}{l}7 \cdot 25 \\
5 \cdot 10 \\
4 \cdot 07\end{array}$ & $\begin{array}{l}9 \cdot 08 \\
8 \cdot 50 \\
6 \cdot 15\end{array}$ & $\begin{array}{l}9 \overline{30} \\
7 \cdot 30\end{array}$ & $\begin{array}{l}14 \cdot 0 \\
15 \cdot 30 \\
14 \cdot 0\end{array}$ & $\begin{array}{l}4 \cdot 32 \\
2 \cdot 50\end{array}$ \\
\hline
\end{tabular}

Time in minutes and seconds. $P=0.1 \mathrm{ml}$. of patient's plasma, $H=0.1 \mathrm{ml}$. of haemophilic plasma, $\mathrm{H} / 10, \mathrm{H} / 100, \mathrm{P} / 10, \mathrm{P} / 100=0.1 \mathrm{ml}$ of $1 / 10$ or $1 / 100$ saline dilution of the appropriate plasma, $N / 10=$ $1 / 10$ dilution in saline of normal fresh plasma. 0.1 or $0.2 \mathrm{ml}$. of $\mathrm{CaCl}_{2}$ added as appropriate. $\mathrm{S}=0.1 \mathrm{ml} .0 .85 \%$ saline.

The results in Table IV represent the average figures from a number of experiments on each day on each of a number of different haemophiliacs. They have been separated into batches according to the date the experiments were carried out, because during this period the patient's clotting time was rapidly approaching normal.
In no case when equal parts of the patient's plasma and haemophilic blood were mixed was the clotting time appreciably shorter than the clotting time of the patient's plasma alone. These results may be compared with the definite shortening produced by even a tenth part of normal plasma. It will be seen that a tenth part, or even a hundredth part, of the patient's plasma appears to have some slight effect on the clotting of the haemophilic plasmas, but this effect was not nearly so great as that usually obtained with similar dilutions of normal plasma. It must be concluded that the patient's plasma was grossly deficient in antihaemophilic globulin.

It is known that the clotting defect of haemophilic plasma is apparently corrected by the addition of small quantities of normal plasma. The patient's plasma was found to be markedly corrected by the addition of normal plasma in high dilution, but the degree of correction was perhaps not quite as marked as occurs in true haemophilic blood.

Presence of the Christmas Factor.-The investigation of the reaction of the patient's plasma with haemophilic plasma was delayed until she had nearly recovered, because in the first stages of the investigations (in October, 1951) the patient and a haemophiliac were venepunctured simultaneously and the two bloods mixed in equal proportions. The mixture clotted in $6 \mathrm{~min}$. $45 \mathrm{sec}$., whereas the patient's blood clotted in $31 \mathrm{~min}$. and that of the haemophiliac in $16 \mathrm{~min}$. The prothrombin consumption index-grossly abnormal in the patient and the haemophiliac-was in the mixed blood also corrected almost to normal. The results were amplified by studies of the plasmas. It was only later that this "haemophiliac" was found to be a case of Christmas disease (Biggs, Douglas, Macfarlane, Dacie, Pitney, Merskey, and O'Brien, 1952). The present patient's blood, therefore, does not lack the Christmas factor.

\section{Summary and Conclusions}

The literature of acquired coagulation defects in women is briefly reviewed. A patient had large subcutaneous bruises and haematuria three months after her first confinement. She appeared to have recovered completely four months later. Her bleeding time was rather long and her coagulation mechanism defective. No other abnormality was found. The formation of thrombin was delayed and incomplete, and the prothrombin consumption grossly abnormal. The one- and two-stage prothrombin times were normal, and there was 
no evidence of an inhibitor. The prothrombin was therefore normal, but the ability to form thromboplastin was abnormal. She appeared to lack antihaemophilic globulin, but not the Christmas factor. The platelets must also be regarded as having been abnormal. They were not nearly as efficient as normal platelets in accelerating the clotting of her own high-spun plasma, but were almost as efficient as normal platelets in accelerating the clotting of normal high-spun plasma. Her recovery prevented the fullest investigation, and it is particularly regretted that the thromboplastin generation test (Biggs and Douglas, 1953) had not then been devised.

My thanks are due to Dr. W. A. Lister for permission to investigate and publish this case. I am most grateful to Dr. Rosemary Biggs for her advice and help through all stages of this work.

\section{REFERENCES}

Biggs, R., and Douglas, A. S. (1953). Journal of Clinical Pathology, , 23 . - Dacie, J. V., Pitney, W. R., Merskey, C., and O'Brien, J. R. (1952). Brit. med. J., 2, 1378. and Macfarlane, R. G. (1951). Journal of Clinical Pathology, and 445 .

Congr. Clin. Path. London

Chargaff, E., and West, R. (1946). J. biol. Chem., 166, 189.

Dreskin, O. H., and Rosenthal, N. (1950). Blood, $5,46$.

Fantl, P., and Nance, M. H. (1946). Med. J. Aust., 2125.

Heinle, R. W., Weisberger, A. S., Vignos, P. J., and Holden, W. B. (1949). J. Lab. clin. Med., 34, 1606

Hewlett, J. S., and Haden, R. L. (1949). Ibid., 34, 151.

Joules, H., and Macfarlane, R. G. (1938). Lancet, 1, 715.

Koller, F., Loeliger, A., and Duckert, F. (1951). Acta haemat., Basel, 6, 1.

Madison, F. W., and Quick, A. J. (1945). Amer. J. med. Sci., 209, 443.

Merskey, C. (1950) Journal of Clinical Pathology, 3, 130.

O'Brien, J. R. (1950). Ibid., 4, 272

Tocantins, L. M., Carroll, R. T., and Holburn, R. H. (1951). Blood, $\mathbf{6}, 720$. 